\title{
Retailers Satisfaction and Product Movement of Maggi Noodles in Tenkasi District
}

\author{
Dr. S. Tephillah Vasantham ${ }^{1 *} \&$ Arul Selvan ${ }^{2}$ \\ $I^{*}$ Assistant Professor, ${ }^{2}$ II MBA Student, Department of Management Studies, \\ Mepco School of Management Studies, Mepco Schlenk Engineering College, Sivakasi, Tamilnadu, India.
}

Copyright: () 2022 Dr.S.Tephillah Vasantham \& Arul Selvan. This is an open access article distributed under the terms of the Creative Commons Attribution License, which permits unrestricted use, distribution, and reproduction in any medium, provided the original author and source are credited.

\section{ABSTRACT}

Over the many times, the polls have been a quick food in lots of factors of the world. Now an autumn the alternate of customer preference, taste and ingesting habit also is being modified due to the modernization. Wheat pate the primary conception of the pate came in the Japan. Innovation endured and polls drafted from kudzu have been advanced in the Japan. Ramen polls end up so notorious in Japan. Eventually Instant polls had been constructed and first retailed in Japan. Nestle India Limited, the Indian attachment of the global Fast moving consumer goods most important, Nestle SA, delivered the Maggi brand in India when you consider that 1982, with its launch of Maggi 2 mins pate, an immediate pate product. These have a look at attempts to assay the retailer's position of pleasure on shopping Maggi polls. It was observed using a pre- grounded questionnaire to realize the retailer's perception. For this have a look at, 81 outlets have been don't forget as a sample. For the evaluation cause, statistical outfit and strategies like chi-square, weighted common are used. The shops' delight is right with vacuity and credit content of the Maggi polls and the Movement of the Maggi polls a many of the customer on behalf of the taste, brand name and reasonable figure of the Maggi polls.

\section{Introduction}

The market actually refers to a setup where ability buyers and sellers can meet to exchange items or offerings. It is essentially a medium that facilitates these transactions in an economic system. It lets in for the exchange of goods, offerings and data below the protection of the law and usually in change for consideration. Marketing refers to activities a business enterprise undertakes to promote the shopping for or promoting of a products or services. Marketing consists of advertising and marketing, selling, and delivering merchandise to clients or different corporations. Here the needs and wants of the purchaser are heard, and for that reason, products and services are supplied to them. People engage with each different to change items and offerings they require in exchange for money. There is not any force or coercion, people will choose this merchandise.

Marketing is the procedure of having the right goods or services or ideas to the right humans at the proper region, time, and rate, using the right promoting techniques and utilizing the ideal human beings to provide the customer support related to those items, offerings, or ideas. This concept is called the "proper" principle and is the premise of all advertising method. We can say that advertising is finding out the needs and wants of potential customers (whether agencies or consumers) after which imparting items and services that meet or exceed the expectations of those consumers.

\section{Review of Literature}

Fauziah eddyono and Budiarto subroto (2014) [1], states that a case study of trouble primary food diversification in Indonesia has been found out that the inordinate demand for rice in Indonesia these days calls the authorities to offer occasion reflections product for neighbourhood request. The authority's reflections diversification program, amongst different effects, consists of the persuasion for guests to recollect polls except rice of their important menu. This study explores consumer's conduct of steal polls. Four predictors are bandied, which correspond to 
pricing, creation, distribution channels and fitness troubles. The choice of repliers come carried out the operation of comfort slice, wherein repliers had been decided on due to their presence on the time and region in which the studies is being carried out. This studies is explicatory studies this is the operation of descriptive and verification ways. In undertaking descriptive studies, the studies are the operation of cross-sectional design. The studies statistics had been reused and anatomized the operation of structural equation modelling (SEM). Parameter interpretation estimation of system comes two step fashion to get conformational element evaluation (CFA) after which restate the interpretation with inside the flowchart (mongrel models).

Statistical evaluation that issued to reply the studies pretensions are the $\mathrm{t}$ - check and $\mathrm{F}$ check. T-Check come used to probe the have an effect on of figure, creation, distribution channels, and fitness troubles on buy conduct of polls. Meanwhile, the F- check is carried out to probe the maximum dominant rudiments in forming buy conduct of polls. This study adopts descriptive and verification ways and statistics are anatomized the operation of Structural Equation Modelling (SEM). The take a look at identifies that guests are neglecting their fitness trouble and ignoring figure element in ingesting polls.

Shubhendu shekhershukla and Sandhya Sinha (2020) [10], Consumer's mindfulness towards instant polls brands on the taste and preference, This paper is agitating roughly the brand fidelity of consumer towards the incontinently reflection product like incontinently pate and different product, the look at has been performed with inside the Lucknow and close by sections. All the repliers had been privy to incontinently pate. The look at says that the geared up vacuity and much lower time of guidance had been the primary motive to ingesting the incontinently pate product. There are numerous sources to buy this product with inside the pastoral place and concrete place because of the strong distribution channel.

The common in line with capita buy and in line with capital expenditure on incontinently reflections product had high quality courting with the earnings of ménage. Utmost of the cases housewives are the primary selection maker to buy the incontinently pate and also maturity of the incontinently pate consumer are belonged to better fidelity group. Instant pate began from Japan with inside the 1980's still now an autumn it's far determined to the kitchen of each Indian ménage. Instant pate is not stylish the clean to prepare regale still indeed have an expansive function and region with inside the own circle of cousins festivity. This look at end result is that massive no of mortal beings apprehensive of the incontinently pate with inside the pastoral place and conscious the totem like Maggi, zenith ramen, yippee noodles and maturity of the mortal beings are brand pious.

Shareena P and Mustiary begum (2017) [9], consumer's perception towards Maggi instant polls after its prelaunch, The study makes a thing of perception on consumer toward the Maggi polls before than the ban and later prelaunch of Maggi polls and to observe the purchaser shopping for conduct and amenability to buy Maggi polls after its ban. Data for the study has been gathered from the ninety three Post graduate council scholars from exclusive aqueducts with the help of established questionnaire using present evaluation of the records.

In the evaluation of records maturity of the guests have fed on yippee polls presently observed with the aid of using Maggi polls. Taste is the maximum vital issue at the same time as deciding on immediate polls. This have a look at located that flavour of the Maggi is not always true as after its prelaunch. They have a look at display that guests 
need Maggi to be with inside the business and they are inclined to pay the equal with inside the fortune simplest in the event that they correspond of element which might be good for fitness of the guests.

A study on retailers' perception towards original brands of named FMCG product, the study changed into performed on outlets to fete their perception closer to original brands. The study used a pre-structured questionnaire to fete store perception. The compass of the study is to discover store notion on near to neighbourhood brands of Data has been gathered from the small and unorganized outlets with the aid of using private interviews. The adventure examine is to offer a perception to original brands in FMCG.

The slice system used right then changed into Convenience Sampling, Which is one of the maximum generally used non-opportunity pattern design. The data gathered in shape of questionnaires changed into tabulated and anatomized the operation of abecedarian statistical fashion probabilities. The study discovered that outside of the unorganized outlets are promoting original brands in FMCG sectors. Retailers are not getting that lot income perimeters from original chocolate brands. Maturity of the Retailers is happy with the original brands in swab, snacks and chocolates. So the study is suggesting in addition studies on a big scale to fete the eventuality of original brands.

Ibrahim of Ossu-Bouteng (2020) [5], Influence of consumers' trade creation on consumers' copping of the merchandising of consumer goods in team, Ghana, The primary thing of the study is to observe the have an impact on of purchaser deals creation on consumers buying in merchandising of client goods. The thing of the study is to observe the connection among purchaser deals creation and consumers shopping conduct in merchandising of purchaser goods.

To pick out the kind of consumer income advertising hired through pots selling consumer goods. To pick out the connection among client support and guests copping in merchandising of purchaser goods. The major source of data for the have a look at turned into the sphere check. A close-concluded dependent questionnaire and interviews had been employed in sporting out the check. Convenience slice approach turned into used to acquire data.

\section{Objectives}

(a) To study the factors influencing the retailers buying preference towards Maggi noodles.

(b) To analyse the retailers' level of satisfaction on purchasing Maggi noodles.

(c) To analyse the movement of Maggi noodles among the consumers.

\section{Scope of the Study}

(a) This study will be helpful for the retailers to know their customers preference.

(b) It will be helpful for the retailers to identify the needs of the customers thereby gaining more customers.

(c) This study will be useful for other students who are doing research in the related area.

(d) The study will throw light on the various factors influencing the brand preference.

(e) It is also helps to know about the retailers' opinion with regard to the particular product taken for the study. 


\section{Research Methodology}

Research methodology discusses the method and procedure to collect the data in order to achieve the aims and objectives of this study. This chapter includes research design and instruments data collection methods, sampling design and analysis tools.

\subsection{Research design}

Descriptive research is used in the study to analyse the retailers' perception on movement of Maggi noodles in Tenkasi district, Tamil Nadu. The data collected for this research is purely based on primary and secondary sources.

\subsection{Nature of data}

Primary data and secondary data are used in this research.

\subsection{Primary data}

The information required for this research is collected from retailers through questionnaires.

\subsection{Secondary data}

Secondary data is collected from company report, periodicals, journals, magazines and websites.

\subsection{Method of data collection}

(a) Primary data was collected by direct survey method using the structured questionnaire from the retailers.

(b) Secondary data was collected from the company records, reports, newspapers, files, magazines, periodical and websites.

\subsection{Data collection instrument}

A well-structured questionnaire has been designed which is used to collect the data from retailers.

\subsection{Sampling design Population size}

The population size for study is unknown.

\subsection{Sample size}

The sample size of the study is 81 .

\subsection{Sample method}

The sampling method used is convenience sampling.

\subsection{Sampling Time}

The sampling time is from $10 / 09 / 2021$ to $03 / 10 / 2021$.

\subsection{Tools used for analysis}

Data collected through questionnaire was analysed using tools present in Statistical package for social sciences software. The tools that are used for this study are weighted average test. 


\section{Data Analysis}

\subsection{Weighted Average}

\section{Product}

\begin{tabular}{|c|c|c|c|}
\hline S. No. & Factors & Average & Rank \\
\hline 1 & Less Cooking Skill Is Needed For Maggi. & $\mathbf{1}$ \\
\hline 2 & $\begin{array}{c}\text { Consumer Prefer Maggi Noodles Because The Masala Paste Tastes } \\
\text { Good. }\end{array}$ & 4.901 & $\mathbf{2}$ \\
\hline 3 & $\begin{array}{c}\text { Many Varieties Are Available Based On The Consumers' Need And } \\
\text { Preference }\end{array}$ & 4.802 & $\mathbf{4}$ \\
\hline 4 & The Product Has Higher Demand Among Consumers & 4.790 & $\mathbf{5}$ \\
\hline 5 & $\begin{array}{c}\text { The Packing Of Noodle Attracts The Consumer And } \\
\text { Preserves The Noodles }\end{array}$ & 4.630 & $\mathbf{6}$ \\
\hline 6 & Quantity Is More Than Other Noodles & 4.605 & $\mathbf{7}$ \\
\hline 7 & Maggi Noodles Is Suitable For All Climatic Conditions & 4.550 & $\mathbf{8}$ \\
\hline 8 & Quality Of The Maggi Noodles Is Good & 4.148 & ( \\
\hline
\end{tabular}

\section{Inference}

It is inferred from the above table that the less cooking skill is needed for Maggi noodles ranks the most and has attracted the retailers to purchase the particular brand and the feature of quality of the noodles ranks the least.

Price

\begin{tabular}{|c|c|c|c|}
\hline S. No. & Factors & Average & Rank \\
\hline 1 & Price of the product is Reasonable & 4.7 & $\mathbf{1}$ \\
\hline 2 & Price Will Be Refunded For The Damaged Product & 4.2 & $\mathbf{2}$ \\
\hline 3 & Based On The Purchase Of Maggi Noodles From Wholesaler \\
Discounts Are Offered & 2.5 & $\mathbf{3}$ \\
\hline 4 & Maggi Has More Profit Because Of Its High Demand & 2.3 & $\mathbf{4}$ \\
\hline
\end{tabular}

\section{Inference}

It is inferred from the above table that the price of the Maggi noodles ranks the most and has attracted the retailers to purchase the particular brand name and with profit of its high demand ranking least. 
Place

\begin{tabular}{|c|c|c|c|}
\hline S. No. & Factors & Average & Rank \\
\hline 1 & Whether The Product Is Available In My Place & 4.98 & $\mathbf{1}$ \\
\hline 2 & Maggi Has The Wider Distribution All Over The City & 4.96 & $\mathbf{2}$ \\
\hline 3 & Relationship With Supplier & 4.78 & $\mathbf{3}$ \\
\hline 4 & Frequency of Visit or Interaction by Company Sales \\
\end{tabular}

\section{Inference}

It is inferred from the above table that the Maggi noodles available in my place ranks the most and has attracted the retailers the most to purchase the particular brand and the feature of frequency visit or interaction by company sales representative ranks the least.

\section{Promotion}

\begin{tabular}{|c|c|c|c|}
\hline S. No. & Factors & Average & Rank \\
\hline 1 & I Prefer The Product Because Of Its Brand Name & 4.89 & $\mathbf{1}$ \\
\hline 2 & $\begin{array}{c}\text { Credit Sale Is Available From The Wholesaler Or } \\
\text { Distributor }\end{array}$ & 4.77 \\
\hline 3 & Their Promotional Tactics Plays A Big Role In My Perception & 4.57 & $\mathbf{3}$ \\
\hline 4 & Consumer Are More Attracted To The Appearances Of Maggi & 4.36 & $\mathbf{4}$ \\
\hline 5 & The Slogan Of Maggi Makes The Consumers To Buy The Product & 3.86 & $\mathbf{6}$ \\
\hline 6 & I Recommended This Product To Other Retailers & 3.28 & $\mathbf{7}$ \\
\hline 7 & The Company Provide Rewards Based On Achieving Budget Sale & 2.44 & $\mathbf{3}$ \\
\hline
\end{tabular}

\section{Inference}

It is inferred from the above table that the reason for preferring the for its brand name ranks the most and has attracted the retailers the most to purchase the particular brand and the feature of the company provide rewards based on achieving budget sale ranks the least. 
Consumer Satisfaction

\begin{tabular}{|c|c|c|c|}
\hline S. No. & Factors & Average & Rank \\
\hline 1 & I have regular customers exclusively for Maggi noodles & 4.90 & $\mathbf{1}$ \\
\hline 2 & Maggi noodles have increased brand loyalty & 4.85 & $\mathbf{2}$ \\
\hline 3 & My customers trust Maggi noodles over other brands & 4.78 & $\mathbf{3}$ \\
\hline
\end{tabular}

\section{Inference}

It is inferred from the above table that the retailers having customers exclusively for Maggi noodles ranks the most and has attracted the retailers the most to purchase the particular brand and the feature of customers trust Maggi noodles over other brands ranks the least.

\section{Average Rating of All Variables}

\begin{tabular}{|c|c|c|c|}
\hline S. No. & Factors & Average & Rank \\
\hline 1 & Place & 4.86 & 1 \\
\hline 2 & Consumer satisfaction & 4.84 & 2 \\
\hline 3 & Product & 4.68 & 3 \\
\hline 4 & Promotion & 4.02 & 4 \\
\hline 5 & Price & 3.43 & 5 \\
\hline
\end{tabular}

\section{Inference}

It is inferred from the above table that the place factor ranks the most and has attracted the retailers the most to purchase the particular brand and the feature of price ranks the least.

\section{Summary of Findings}

To study the factors influencing the retailers buying preference towards Maggi noodles.

(a) Most of the consumers are attracted by the taste of the Maggi noodles (54\%) and its brand name (46\%).

(b) Majority of the retailer opinion is the price of the Maggi noodle is reasonable.

(c) Most of the consumer prefer Maggi noodle because of its brand name.

(d) To analyse the retailer's level of satisfaction on purchasing Maggi noodles.

(e) Retailers have overall satisfaction with the movement of Maggi noodles in their outlet faster when compared to other brands.

The Maggi noodle is available in many places and it has the wide distribution all over the Tenkasi district. 
(a) To analyse the movement of Maggi noodles among the consumers. (b) Majority of the retailer have regular customers exclusively for Maggi noodle. (c) Majority of the retailer sell more than 3 Maggi noodle pocket in their retail outlet. (d) Most of the consumers (94\%) don't give any complaint about Maggi noodles.

\section{Suggestion}

(a) The frequency of sales person visit for retail outlet can be further more increased. (b) The company provides some rewards to the retailer based on achieving their budget sale.

\section{Limitations}

(a) The study focuses only on retailers' opinion on brand preference and it would be letter if the study has been extended to get the customers opinion also. (b) The location of the study is limited to Tenkasi district only. (c) The study is only on the Brand preference and it would be more appropriate to undertake study in the future as brand equity, brand image and other branding concepts.

\section{Conclusion}

The sale of Maggi noodles has increased substantially. Calculated data reveals that $96 \%$ of consumers don't give any complaint about Maggi noodles. Price is one of the important factors that are influencing the retailers to prefer buying Maggi noodles. The retailers have overall satisfaction with the movement of Maggi noodles in their outlet faster when compared to other brands. It provides researchers a very good insight about the product movement of Maggi noodles and project students as how to proceed with the project.

\section{Declarations}

\section{Source of Funding}

This research did not receive any grant from funding agencies in the public, commercial, or not-for-profit sectors.

\section{Competing Interests Statement}

The authors declare no competing financial, professional and personal interests.

\section{Consent for publication}

Authors declare that they consented for the publication of this research work.

\section{Bibliography}

[1] Fauziah Eddyono, B.S. (2014). Purchase behaviour of noodles: A Case Study of Effort Primary Food Diversification in Indonesia. International Journal of Science and Technology.

[2] Gur, A. (2020). The study of impact of covid-19 on the consumer purchase behavior of FMCG products. Pal arch's journal of archaeology of egypt/egyptology.

[3] Kajal Chatterjee, K.A. (2017). Identification and Analysis of Factors Affecting Consumer Behavior in Fast Moving Consumer Goods Sector. Business perspective. 
[4] Kharti, D.B. (2015). Consumer attitude and behaviour towards instant noodles especially Maggi in India. EPRA International journal of economics and business review.

[5] Boateng, I. (2020). Influence of Consumer Sales Promotion on Consumers' Purchasing Behaviour of the Retailing of Consumer Goods in Tema, Ghana. Journal of Marketing Management.

[6] Patra, D.G. (2016). Distribution and Promotion Effectiveness on Sales-A Study of Retailer. Splint International Journal of Professionals.

[7] Rajanikanth, M. (2015). A study on retailers perception towards local brands. International Journal Business Quantitative Economics and Applied Management Research.

[8] Rajneesh Suri, J.Z. (2011). Retailers' Merchandise Organization and Price Perceptions. Journal of Retailing.

[9] Shareena P (2016). Consumers' Perception towards Maggi Instant Noodles. Indian Journal of Research.

[10] Shubhendu Shekher Shukla (2020). Consumer's awareness towards instant noodle brands: on the basis of taste and preferences.

[11] Wutan Huatan Jisuan Jishu. Tandon, P.M. (2019). Maggi -from muddle to magic - a study of brand image and consumer preference towards Maggi noodles in the post-ban prelaunch phase. International Journal of Advance and Innovative Research. 